\title{
O n-butil cianoacrilato na lobectomia pulmonar parcial em felinos. Estudo experimental
}

\author{
The n-butyl cyanoacrilate in partial lung lobectomy in cats. Experimental study
}

\author{
Marcos Makoto Ishizaki ${ }^{1}$ Ana Maria Reis Ferreira² ${ }^{2}$ Edgard Salomão Júnior ${ }^{3}$ \\ Amary Nascimento Júnior ${ }^{4}$ Firmino Marsico Filho $^{5}$
}

\section{RESUMO}

O presente estudo teve como objetivo verificar a viabilidade do n-butil cianoacrilato na pneumostasia $e$ hemostasia em lobectomia pulmonar parcial. Foram utilizadas seis gatas hígidas, adultas, com peso médio de três quilogramas. O procedimento cirúrgico consistiu na realização de toracotomia intercostal com lobectomia pulmonar parcial em que se utilizou adesivo cirúrgico para fechamento do lobo pulmonar. Após 21 dias da cirurgia, os animais foram novamente submetidos à toracotomia para a coleta de fragmento da região onde o adesivo fora aplicado, para análise histopatológica. Foram realizadas radiografias de tórax das pacientes para o acompanhamento pré e pós lobectomia pulmonar parcial e, aos dois, sete, 14 e 21 dias subseqüentes. As alterações radiográficas e clínicas encontradas como pneumotórax residual, aumento na densidade pulmonar, enfisema subcutâneo e apatia foram corrigidas em tempo hábil, não comprometendo os resultados do estudo. A histopatologia evidenciou reação inflamatória com predomínio de células mononucleares, neovascularização, proliferação de tecido conjuntivo e pequenas áreas de enfisema e atelectasia, sem comprometimento clínico significativo. Concluiu-se que o cianoacrilato é capaz de produzir adequada pneumostasia e hemostasia, e poderá ser uma opção para a realização de lobectomia pulmonar parcial em felinos.

Palavras-chave: cirurgia, adesivo, aerostasia pulmonar, tórax.

\begin{abstract}
The n-butyl cyanoacrilate tissue adhesive was used in this study aiming to verify the viability of its use for hemostasis and to avoid air leakage in partial lung lobectomy. Six healthy adult female domestic shorthair cats, weight range of three $\mathrm{kg}$ were submitted to an intercostal thoracotomy with partial lung lobectomy using n-butyl cyanoacrilate to close the lobe. After 21 days they were submitted to another thoracotomy to collect a fragment of the lung where the adhesive was applied to a histopathological study. Chest films were taken pre and post partial lung lobectomy and at two, seven, 14 and 21 days as a follow up procedure. Radiographical and clinical changes such as residual pneumothorax, increase in pulmonary density, subcutaneous emphysema and apathy were corrected in due time, not compromising the study. The histopathology results showed an inflammatory reaction with mononuclear prevailing, neovascularization, spread of connective tissue and small areas of emphysema and atelectasy, with no significant clinical signs. The conclusion was that the cyanoacrilate adhesive may control the air leakage and hemorrhage and can be an option for sutureless partial lung lobectomy.
\end{abstract}

Key words: surgery, adhesive, pulmonary air leakage control, thorax.

${ }^{1}$ Médico Veterinário, Mestrando da Faculdade de Veterinária (FV), Universidade Federal Fluminense (UFF), Rua Marques de Abrantes, 177/504, 22230-060, Rio de Janeiro, RJ. E-mail: marcosmakoto@medcenter.com

${ }^{2}$ Médico Veterinário, MSc, Doutora Professora Adjunta, Departamento de Patologia, FV, UFF, Pesquisadora 2C do Conselho

Nacional de Desenvolvimento Científico e Tecnológico (CNPq). E-mail: anamrferreira@openlink.com.br

${ }^{3}$ Médico Veterinário, Mestrando da FV, UFF.

${ }^{4}$ Médico Veterinário, MSc, Professor Assistente, Disciplina de Técnica Cirúrgica e Anestesiologia, FV, UFF.

${ }^{5}$ Médico Veterinário, MSc, Doutor Professor Adjunto Disciplina de Técnica Cirúrgica e Anestesiologia, FV, UFF, Pesquisador 2B CNPq. In memorian. 


\section{INTRODUÇÃO}

A lobectomia pulmonar pode ser utilizada em casos de neoplasias, abscessos, lacerações pulmonares, torção pulmonar, corpos estranhos, atelectasia irreversível, fístulas bronco-esofageanas e pneumotórax espontâneo (LA RUE et al., 1987; NELSON, 1993; ORTON, 1995; FERREIRA-FILHO et al., 1997; NEATH et al., 2000).

A técnica convencional para uma lobectomia pulmonar parcial é a ressecção da parte afetada e sutura da porção remanescente do lobo com fios absorvíveis em padrão contínuo horizontal e, se necessário, sobreposição de camadas, para evitar o extravasamento de ar (FOSSUM, 1997). Como alternativa, pode-se utilizar grampeadores pulmonares (NELSON, 1993; BIRCHARD \& SCHERTEL, 1994; WITHROW, 1996; FERREIRA-FILHO et al., 1997, FOSSUM, 1997) embora a disponibilidade e o custo sejam fatores que limitem seu uso na rotina (ORTON, 1996).

A primeira descrição de um grupo de adesivos chamado de cianoacrilato (CA) foi em 1949 por Ardis apud DEBONO (1997). Estes adesivos são polimerizados devido a uma reação exotérmica em contato com tecidos ou fluidos, formando uma substância plástica flexível e insolúvel, que se adere firmemente à superfície úmida e funciona como agente hemostático eficiente (QUINN et al., 1997).

Os cianoacrilatos são adesivos biodegradáveis, bacteriostáticos e hemostáticos, e causam menos reação de corpo estranho e inflamação clínica do que a sutura convencional (LEHMAN et al., 1966; BONUTTI et al., 1988; QUINN et al., 1993; SYLLOS et al., 1996; HORSLEY \& MILLER, 1997). Segundo SILVER (1976), os CA parecem estimular a cicatrização epitelial que ocorre sob o adesivo e são eliminados quando a reparação está completa. Não há relatos de efeitos tóxicos ou carcinogênicos em relação ao uso de CA de cadeia longa (QUINN et al., 1997).

Há algumas décadas, a utilização de adesivos de pele, cuja base é cianoacrilato, tem sido descrita em diversas áreas cirúrgicas (BONUTTI et al., 1988). Porém, há uma escassa literatura sobre utilização em pulmões (HORSLEY \& MILLER, 1997) e, embora venha sendo estudado em diversas espécies animais, não são relatados estudos em felinos.

O objetivo deste estudo é avaliar a viabilidade da utilização do adesivo cirúrgico n-butil cianoacrilato (Vetbond $^{\circledR}, 3 \mathrm{M}$ do Brasil) na pneumostasia e hemostasia em lobectomia pulmonar parcial em gatos.

\section{MATERIAL E MÉTODOS}

Foram utilizadas seis gatas com idade entre um e três anos, com peso médio de $3 \mathrm{~kg}$, sem raça definida, provenientes do Centro de Controle de Zoonoses (Niterói, RJ). Todas as pacientes foram submetidas às avaliações clínicas e laboratoriais, sendo vermifugadas antes dos procedimentos pré-operatórios. Os exames pré-operatórios incluíram hemograma, contagem de plaquetas e bioquímica sérica (alanina aminotransferase, creatinina, uréia, proteína total e glicose).

O estudo foi conduzido de acordo com as normas de vivissecção de animais descritas pelo Colégio Brasileiro de Experimentação Animal (FIGUEIREDO et al., 1979). Todos os animais foram mantidos em gatis individuais, forrados e arejados com bandejas com granulado sanitário, com alimentação e água ad libitum em comedouros. Os animais foram observados duas a três vezes ao dia, durante todo o período de internação, e tinham acesso a banho de sol, sendo mantidas soltas durante algumas horas diariamente para exercícios. A alimentação foi mantida com ração seca industrializada (Eukanuba ${ }^{\circledR}$ Adult Cats) durante todo o período do experimento. Nos cinco primeiros dias após os procedimentos cirúrgicos, administrou-se em conjunto com a ração seca, ração pastosa com níveis calóricos e protéicos superiores (Eukanuba ${ }^{\circledR}$ Maximum Calorie).

Todas as pacientes foram identificadas por códigos referentes à ordem das cirurgias, de M1 a M6, e todos os dados foram registrados em fichas individuais. As pacientes foram submetidas a jejum alimentar de doze horas e hídrico de duas horas antes de cada procedimento cirúrgico. Os animais foram prémedicados com cloridrato de cetamina na dose de $10 \mathrm{mg}$ $\mathrm{kg}^{-1}$ intramuscular e induzidos com propofol na dosagem de $2 \mathrm{mg} \mathrm{kg}^{-1}$, intravenoso, e a manutenção foi realizada com uso de isoflurano. Foi utilizado o besilato de atracúrio $\left(0,1 \mathrm{mg} \mathrm{kg}^{-1}\right)$ intravenoso como bloqueador neuromuscular.

Foi realizada ampla tricotomia na região torácica esquerda seguida de procedimentos de rotina de assepsia. A via de acesso ao pulmão foi obtida através de uma toracotomia intercostal esquerda no quinto espaço. O lobo pulmonar caudal esquerdo foi exposto e isolado com auxílio de compressas. Tal estrutura foi fixada com pinça vascular de DeBakey curva de $11 \mathrm{~cm}$. Realizou-se então uma incisão no lobo pulmonar paralela às superfícies de apreensão da pinça para a sua retirada. $\mathrm{O}$ fragmento pulmonar retirado foi fixado em formol a $10 \%$. Cerca de $0,5 \mathrm{ml}$ do adesivo cirúrgico foi instilado sobre o sítio da excisão do frag- 
mento pulmonar previamente seco e sem resquícios de sangue, em uma passagem. A hemostasia e pneumostasia foram comprovadas através da instilação de soro fisiológico. Por não ser estéril externamente, o frasco do Vetbond ${ }^{\circledR}$ foi colocado em um dedo de luva esterilizada para o manejo do cirurgião, mantendo a assepsia. Foi colocado um dreno torácico para restaurar a pressão negativa intratorácica e a síntese da parede costal foi realizada conforme descreve FOSSUM (1997).

As pacientes foram mantidas em observação com a finalidade de detectar possíveis alterações no padrão respiratório durante as primeiras 12 horas. A fluidoterapia foi mantida até a estabilização hemodinâmica das pacientes observada por meio da palpação de pulso e da frequiência cardíaca. A profilaxia antimicrobiana foi efetuada com amoxicilina trihidratada ao término do procedimento cirúrgico, na dosagem de $20 \mathrm{mg} \mathrm{kg}^{-1}$, a cada 12 horas, pela via subcutânea, por sete dias. Para a analgesia, foi utilizado o cloridrato de tramadol na dose de $2 \mathrm{mg} \mathrm{kg}^{-1}$, a cada 12 horas, por via intramuscular durante cinco dias.

Vinte e um dias após a cirurgia, os animais foram novamente submetidas à toracotomia, com os mesmos protocolos anestésico e cirúrgico, com a finalidade de observar macroscopicamente e coletar um fragmento pulmonar do local onde foi aplicado o adesivo cirúrgico.

As pacientes foram avaliadas clinicamente, de forma subjetiva, para verificar a presença de dor, através da presença de midríase, inapetência, vocalização, apatia e desconforto torácico, sendo tais observações mantidas por 12 horas após a cirurgia.

Avaliou-se a qualidade respiratória por meio da observação da amplitude de ventilação, mobilidade torácica e padrão respiratório (bradipnéia, taquipnéia ou dispnéia) no pós-operatório imediato (primeiras 12 horas) e nos dias subseqüentes às cirurgias.

Foram realizadas avaliações radiográficas simples, nas projeções látero-lateral e dorsoventral antes de cada procedimento cirúrgico (controle), no dia da cirurgia (dia zero) e, aos dois, sete, 14 e 21 dias subseqüentes à operação, avaliando-se a presença de pneumotórax, aumento da densidade pulmonar na região correspondente ao lobo pulmonar caudal esquerdo e presença de enfisema subcutâneo, no local onde foi realizada a toracotomia. As alterações foram graduadas de acordo com os padrões radiográficos em relação ao controle e classificadas em discreta, moderada, acentuada ou ausente.

O fragmento pulmonar coletado foi clivado, processado e incluído em parafina. Os cortes histológicos foram corados pelas técnicas de hematoxilina e eosina (HE), ácido periódico e reagente de Schiff (PAS) e, tri-crômico de Gomori (TG). O material coletado na primeira cirurgia foi definido como fragmento pulmonar normal (PN) e, o material coletado na segunda cirurgia foi definido como fragmento pulmonar com o adesivo cirúrgico (PC).

Cerca de três semanas após a segunda cirurgia, as pacientes foram novamente vermifugadas $\mathrm{e}$ vacinadas, e submetidas à ovariosalpingohisterectomia para posterior adoção.

\section{RESULTADOS}

Não foram observadas intercorrências no período trans-operatório. Apenas uma paciente (M3), durante o segundo procedimento cirúrgico, apresentou pequena aderência da área pulmonar à parede torácica, no espaço intercostal correspondente à toracotomia. Esta foi desfeita manualmente, preservando-se as estruturas anatômicas. Apesar desta condição, não foram notadas alterações quanto à mobilidade torácica e aos parâmetros respiratórios como amplitude de ventilação e freqüência respiratória (bradipnéia, taquipnéia ou dispnéia).

Clinicamente, todas as pacientes recuperaram-se bem dos procedimentos cirúrgicos. Durante o período pós-operatório de 12 horas, foi observada a presença de apatia leve nos pacientes, porém não demonstraram outros sinais como vocalização ou falta de apetite. Imediatamente após a detecção dessa apatia, foi realizada a medicação analgésica. Os exames clínicos de rotina também não evidenciaram sinais respiratórios tais como dispnéia, taquipnéia ou bradipnéia, ou midríase.

$\mathrm{Na}$ avaliação radiográfica das seis pacientes, realizadas antes da lobectomia pulmonar parcial (radiografia de controle), evidenciou-se silhueta cardíaca, traquéia e pulmões sem alterações dignas de nota em todos os animais. Os resultados das radiografias realizadas imediatamente após a lobectomia pulmonar parcial (dia zero) e nos dias dois, sete, $14 \mathrm{e}$ 21 estão descritos na tabela 1.

O exame macroscópico do material coletado na primeira cirurgia revelou fragmentos pulmonares de coloração rósea, com aspecto e consistência condizente com a higidez das pacientes (PN). O exame microscópico destes fragmentos revelou a presença de hiperemia, atelectasia e pequenas áreas de enfisema.

O material coletado 21 dias após a primeira cirurgia (PC) apresentou uma área linear, de coloração ligeiramente azulada e de consistência endurecida, correspondendo ao local onde foi aplicado o adesivo cirúrgico. Ao redor da área em que o adesivo foi colo- 
Tabela 1 - Observações radiográficas dos felinos submetidos ao procedimento cirúrgico em relação à presença de pneumotórax, aumento na densidade pulmonar e enfisema subcutâneo, após o procedimento cirúrgico, de acordo com os períodos de observação.

\begin{tabular}{|c|c|c|c|c|c|c|}
\hline Alterações & Pacientes & Dia 0 & Dia 2 & Dia 7 & Dia 14 & Dia 21 \\
\hline \multirow{6}{*}{ Pneumotórax } & M1 & + & - & - & - & - \\
\hline & M2 & ++ & - & - & - & - \\
\hline & M3 & + & - & - & - & - \\
\hline & M4 & - & - & - & - & - \\
\hline & M5 & - & - & - & - & - \\
\hline & M6 & ++ & + & - & - & - \\
\hline \multirow{6}{*}{$\begin{array}{l}\text { Aumento na densidade } \\
\text { pulmonar }\end{array}$} & M1 & ++ & - & - & - & - \\
\hline & M2 & +++ & + & + & + & - \\
\hline & M3 & ++ & - & - & - & - \\
\hline & M4 & ++ & - & - & - & - \\
\hline & M5 & ++ & - & - & - & - \\
\hline & M6 & ++ & + & + & + & - \\
\hline \multirow{6}{*}{ Enfisema subcutâneo } & M1 & - & - & - & - & - \\
\hline & M2 & +++ & + & + & + & - \\
\hline & M3 & + & - & - & - & - \\
\hline & M4 & +++ & + & - & - & - \\
\hline & M5 & + & - & - & - & - \\
\hline & M6 & +++ & +++ & - & - & - \\
\hline
\end{tabular}

(+) discreto; (++) moderado; (+++) acentuado; (-) ausente.

cado, notou-se a presença de uma área esbranquiçada de cerca de $1 \mathrm{~mm}$ de espessura e, abaixo desta, observou-se uma região mais avermelhada em contraste com o pulmão hígido. $\mathrm{Na}$ paciente $\mathrm{M} 3$, além da área esbranquiçada, ainda foi possível observar uma pequena área de aderência com a pleura parietal, no local da incisão na parede torácica.

O exame microscópico de todas as amostras de fragmento PC revelou a ausência do adesivo cirúrgico, sendo observado ao redor do sítio de aplicação do adesivo reação inflamatória constituída predominantemente por células mononucleadas (macrófagos e linfócitos), havendo neovascularização, proliferação de tecido conjuntivo e áreas de hiperemia (Figura 1). No tecido pulmonar adjacente, foi observada presença de pequenas áreas de enfisema e atelectasia semelhante aos dos fragmentos PN. Foi observado, também, um espessamento da pleura visceral que circundava a área da reação inflamatória e reparadora ao adesivo cirúrgico. Não foi observada qualquer alteração na coloração pelo PAS.

\section{DISCUSSÃO}

O emprego de suturas convencionais em lobectomia pulmonar parcial é consagrado (TAKARO, 1984), porém se torna um processo trabalhoso, aumentando os danos causados pela manipulação do órgão, além de promover sangramentos durante a pas- sagem da agulha (HOOD, 1984). FERREIRA-FILHO et al. (1997) afirmam que grampeadores toraco-abdominais permitem a drástica diminuição do tempo anestesiológico e cirúrgico, com menor manipulação do órgão e melhor controle da hemostasia e pneumostasia. Porém, relatam a necessidade de utilizar suturas extras para controle de vazamento de ar e do sangramento. Neste estudo, observou-se que, com a utilização de adesivo cirúrgico, a manipulação do órgão também foi mínima, houve um adequado controle na pneumostasia e hemostasia sem a necessidade de suturas adicionais.

A presença de enfisema subcutâneo pode ocorrer no momento da retirada do dreno torácico por má técnica de fechamento e por movimentação excessiva (JACOBS, 1995). Observou-se enfisema subcutâneo em cinco animais, porém com reabsorção completa após cerca de sete dias. Apenas um animal (M2) apresentou regressão completa após 14 dias. Os autores acreditam que haja uma migração do ar referente ao pneumotórax residual para o espaço subcutâneo levando ao aparecimento do enfisema.

No período pós-operatório, é comum encontrar-se ar, no interior do espaço interpleural, denominado de pneumotórax residual e, que raramente leva à presença de alterações clínicas (ARON \& ROBERTS, 1993; BIRCHARD \& SCHERTEL, 1994). Verificou-se, neste estudo, a presença de pneumotórax residual, avaliada radiograficamente, porém sem sinais clínicos, 


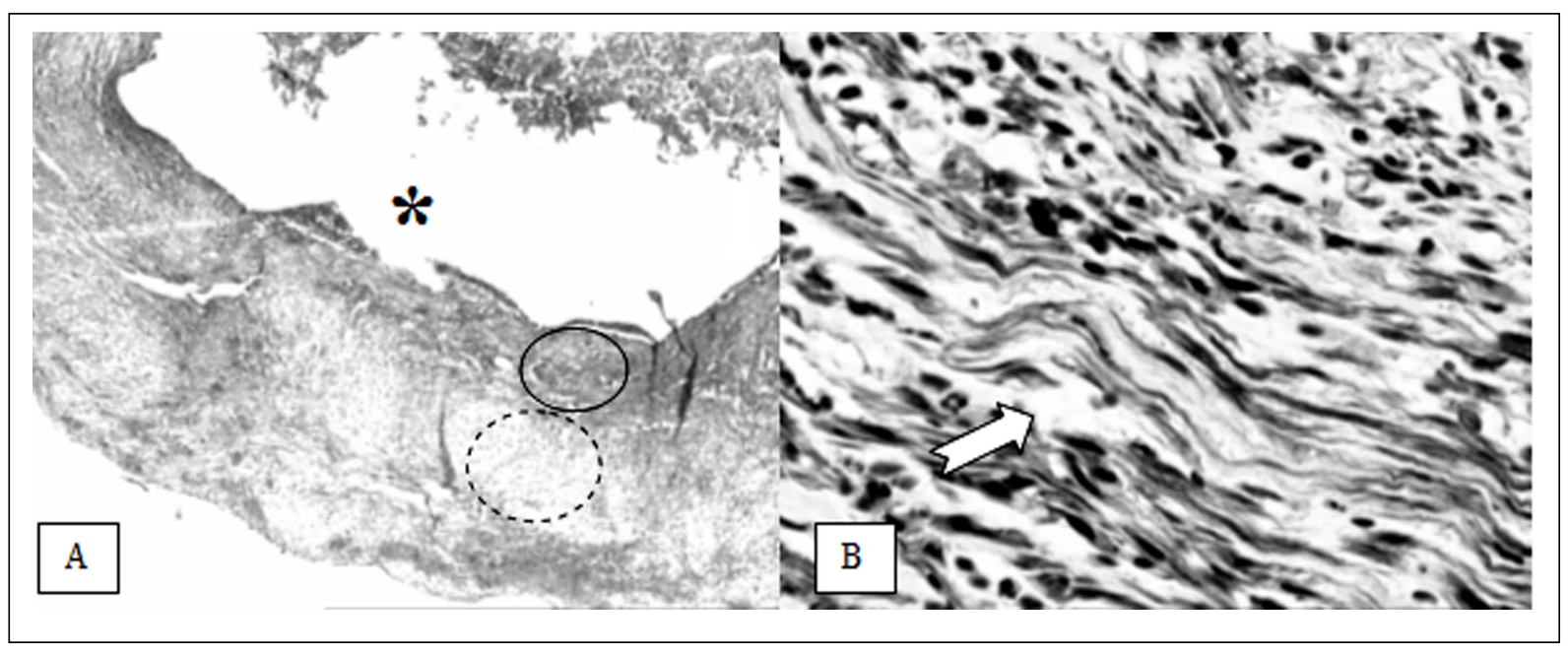

Figura 1 - Fotomicrografia - Fragmento de pulmão felino coletado 21 dias após ter sido submetido a lobectomia pulmonar parcial e uso de cianacrilato para hemostasia e pneumostasia: A - o espaço deixado pelo adesivo (asterisco), infiltrado inflamatório (circulo) e proliferação de tecido conjuntivo (circulo tracejado) (HE - aumento de 40x original); B - Infiltrado inflamatório e proliferação de tecido conjuntivo (seta) (tri-crômico de Gomori - aumento de 400x original).

sendo totalmente reabsorvido ou migrado para o espaço subcutâneo levando à formação de enfisema após dois dias em todos os animais em consonância de estudos realizados por ARON \& ROBERTS (1993) e BIRCHARD \& SCHERTEL (1994), levando a crer que não houve posterior extravasamento de ar dos pulmões manipulados.

FERREIRA-FILHO et al. (1997) observaram experimentalmente em cães, que, quando da utilização de grampeadores tóraco-abdominais em lobectomia pulmonar parcial, foi observada a presença de aderências da pleura visceral no local da incisão em todos os animais, porém sem sintomatologia clínica. Neste estudo, foi observada em um animal, aderência da pleura visceral na região onde foi realizada a toracotomia, sem sinais clínicos evidentes como observado pelos autores citados acima.

PANI et al. (1968), TORIUMI et al. (1990), TEBALA et al. (1995) e DEBONO (1997) constataram em outros tipos de tecidos em humanos a presença de um processo inflamatório crônico discreto e com células gigantes multinucleadas de corpo estranho após 48 a 72 horas da utilização do adesivo cirúrgico. No presente estudo, o material foi coletado 21 dias após, sendo observado um processo inflamatório sob a região onde foi aplicado o adesivo, porém sem a presença de células gigantes multinucleadas, levando a crer que a ocorrência de tais células se deva provavelmente ao tempo de coleta do material.

No presente estudo, foram observadas áreas de reação inflamatória predominantemente mononuclear, com presença de neovascularização. Em estudo com humanos nos quais o CA é implantado em tecidos pouco vascularizados como cartilagem e enxertos ósseos, foi observada discreta reação inflamatória, enquanto que, em tecidos mais vascularizados como o tecido subcutâneo, foi observada reação inflamatória maior (TORIUMI et al., 1991).

A análise histopatológica, deste estudo, evidenciou uma área de reação inflamatória, após 21 dias do procedimento inicial, sendo importante ressaltar a ausência de áreas de necrose. Estudos de TEBALA et al. (1995) evidenciaram proliferação de tecido conjuntivo após 15 dias do procedimento cirúrgico inicial de anastomose intestinal em suínos e, apesar de encontrar uma reação tecidual de corpo estranho e infiltrado de células polimorfonucleares, estes achados foram atribuídos pelos autores aos fios de sutura ou grampos e não ao adesivo. Com a utilização do adesivo, os autores observaram apenas uma reação inflamatória discreta de reação de corpo estranho.

Outros estudos em que foram utilizados outros modelos experimentais como a implantação de enxertos ósseos e de cartilagem em orelhas de coelhos para avaliar a histotoxicidade dos CA (TORIUMI et al., 1990) e fixação de enxertos de pele utilizando CA (DEBONO, 1997), demonstraram reações teciduais semelhantes às encontradas neste estudo, em diferentes períodos de coleta de material para a análise histopatológica.

Estudos na espécie humana de HACHIDA et al. (1987), QUINN et al. (1993) e TEBALA et al. (1995) relataram a ausência de efeitos tóxicos e carcinogenéticos do CA de cadeia longa (quatro ou 
mais carbonos no radical alcoxicarbonil) e diversos testes in vivo e in vitro não detectaram propriedades carcinogênicas desses adesivos. Uma extensa experiência clínica de mais de 30 anos também não relatou malignidade, o que permitiu considerá-lo praticamente sem potencial carcinogenético. Embora o período de 21 dias não seja suficiente para determinar a possibilidade de haver algum potencial de carcinogênese, não existem dados ou informações de pacientes que utilizaram este adesivo por um tempo maior, o que não permite ainda chegar a uma conclusão definitiva a esse respeito. Tampouco foi observado qualquer sinal clínico compatível com toxicidade nas pacientes utilizadas durante o período em que estiveram internadas.

\section{CONCLUSÃO}

De acordo com o protocolo utilizado neste estudo, pode-se concluir que o cianoacrilato, além de produzir uma adequada pneumostasia e hemostasia, pode ser uma opção para a realização de lobectomia pulmonar parcial sem sutura e, o processo de reparação com a utilização de cianoacrilato é satisfatório inclusive quando avaliado histopatologicamente.

\section{AGRADECIMENTOS}

CAPES, 3M do Brasil, Iams Company, Bayer Saúde Animal, Laboratórios Pfizer.

\section{FONTES DE AQUISIÇÃO}

a - Vetbond - 3M do Brasil Ltda. Via Anhanguera, Km 110 Campinas, SP.

b - Eukanuba Adult Cats e Eukanuba Maximum Calorie - Iams Company do Brasil.

\section{REFERÊNCIAS BIBLIOGRÁFICAS}

ARON, D.N.; ROBERTS, R.E. Pneumothorax. In: BOJRAB, M.J. Disease mechanisms in small animal surgery. 2.ed. Philadelphia : Lea \& Febiger, 1993. Cap.68, p.396-403.

BIRCHARD, S.B.; SCHERTEL, E.R. Principles of thoracic surgery. In: BIRCHARD, S.B.; SHERDING, R.G. Saunder's manual of small animal practice. Philadelphia : Saunders, 1994. Cap.25, p.600-606.

BONUTTI, P.M. et al. Isobutyl cyanoacrilate as a soft tissue adhesive: an in vitro study in the rabbit Achilles tendon. Clinical Orthopaedics and Related Research, v.4, n.229, p.241-248, apr, 1988.

DEBONO, R. A simple, inexpensive method for precise application of cyanoacrilate tissue adhesive. Plastic and Reconstructive Surgery, v.100, n.2, p.447-450, 1997.
FERREIRA FILHO, J.A.D. et al. Comparação entre sutura convencional com fio de poliéster e sutura com grampos de aço inoxidáveis na lobectomia parcial pulmonar. Estudo experimental em cães (Canis familiaris). Revista Brasileira de Ciência Veterinária, v.4, n.3, p.127-130, 1997.

FIGUEIREDO, J. et al. Colégio Brasileiro de Experimentação Animal (COBEA). Lei n. 6.638, de 08 de maio de 1979.

FOSSUM, T.W. Surgery of the lower respiratory system: lungs and thoracic wall. In: Small animal surgery. Missouri : Mosby, 1997. Cap.26, p.649-673.

HACHIDA, M. et al. Bronchial anastomosis with a tissue adhesive. Journal Thoracic and Cardiovascular Surgery, v.93, n.3, p.344-349, 1987.

HOOD, R.M. Stapling techniques involving lung parenchyma. Surgical Clinics North America, v.64, n.3, p.469-480, 1984.

HORSLEY, W.S.; MILLER, J.I. Management of the uncontrollable pulmonary air leak with cyanoacrilate glue. Annals Thoracic Surgery, v.63, p.1492-1493, 1997.

JACOBS, G. Cyanosis. In: ETTINGER, S.J.; FELDMAN, E.C. Textbook of veterinary internal medicine. 4.ed. Philadelphia : Saunders, 1995. V.1, cap.42, p.192-197.

LA RUE, S.M. et al. Lung resection using surgical staples in $\operatorname{dogs}$ and cats. Veterinary Surgery, v.16, n.3, p.238-240, 1987.

LEHMAN, A.W. et al. Toxicity of alkyl 2-cyanoacrilates: bacterial growth. Archives of Surgery, v.93, p.447-450, 1966.

NEATH, P.J. et al. Lung lobe torsion in dogs: 22 cases (19811999). Journal American Veterinary Medical Association, v.217, n.7, p.1041-1044, 2000.

NELSON, A.W. Lower respiratory system. In: SLATTER, D. Textbook of small animal surgery. 2.ed. Philadelphia : Saunders, 1993. V.1, cap.53, p.777-803.

ORTON, E.C. Lobectomia pulmonar parcial e completa. In: BOJRAB, M.J. Técnicas atuais em cirurgia de pequenos animais. 3.ed. São Paulo : Roca, 1996. Seção D, cap.22, p. 333-335

ORTON, E.C. Lung. In: Small animal thoracic surgery. Philadelphia : Williams \& Wilkins, 1995. Cap.5, p. 161-168.

PANI, K.C. et al. The degradation of n-butyl alpha cyanoacrilate tissue adhesive. II. Surgery, v.63, n.3, p.481489, 1968.

QUINN, J.V. et al. A randomized, controlled trial comparing a tissue adhesive with suturing in the repair of pediatric facial lacerations. Annals of Emergency Medicine, v.22, n.7, p.1130-1135, 1993.

QUINN, J.V. et al. A randomized trial comparing octylcyanoacrilate tissue adhesive and sutures in the 
management of lacerations. Journal American Medical Association, v.277, n.19, p.1527-1530, 1997.

SILVER, A. Tissue adhesives. Veterinary Record, v.98, p.405-406, 1976.

SYLLOS, D.H. et al. Anastomoses intestinais com Histoacryl: comparação entre anastomose com fio, com fio reforçada por Histoacryl, com uso exclusivo de Histoacryl. Estudo experimental em ratos. Revista Médica, São Paulo, v.75, n.4, p.215-231, 1996.

TAKARO, T. Use of staples in pulmonary surgery. Surgical Clinics of the North America, v.64, n.3, p.461-468, 1984

TEBALA, G.D. et al. The use of cyanoacrilate tissue adhesive in high-risk intestinal anastomoses. Japan Journal of Surgery, v.25, p.1069-1072, 1995

TORIUMI, D.M. et al. Histotoxicity of cyanoacrilate tissue adhesives: a comparative study. Archives Otolaryngology Head Neck Surgery, v.116, p.546550,1990 .

TORIUMI, D.M. et al. Variable histotoxicity of Histoacryl when used in a subcutaneous site: an experimental study. Laryngoscope, v.101, p.339-343, 1991.

WITHROW, S.J. Tumors in the respiratory system. In Small animal clincal oncology. 2.ed.

Philadelphia: Saunders, 1996. Cap.19, p.268-286. 